\title{
Method for Predicting Solubilities of Solids in Mixed Solvents
}

\author{
Ellegaard, Martin Dela; Abildskov, Jens; O'Connell, J. P.
}

\section{Published in:}

AIChE Journal

Link to article, DOI:

10.1002/aic.11759

Publication date:

2009

Document Version

Early version, also known as pre-print

Link back to DTU Orbit

Citation (APA):

Ellegaard, M. D., Abildskov, J., \& O'Connell, J. P. (2009). Method for Predicting Solubilities of Solids in Mixed Solvents. AlChE Journal, 55(5), 1256-1264. https://doi.org/10.1002/aic.11759

\section{General rights}

Copyright and moral rights for the publications made accessible in the public portal are retained by the authors and/or other copyright owners and it is a condition of accessing publications that users recognise and abide by the legal requirements associated with these rights.

- Users may download and print one copy of any publication from the public portal for the purpose of private study or research.

- You may not further distribute the material or use it for any profit-making activity or commercial gain

- You may freely distribute the URL identifying the publication in the public portal

If you believe that this document breaches copyright please contact us providing details, and we will remove access to the work immediately and investigate your claim. 


\title{
Method for Predicting Solubilities of Solids in Mixed Solvents
}

\author{
Martin D. Ellegaard and Jens Abildskov* \\ CAPEC, Department of Chemical and Biochemical Engineering, Building 229, \\ Technical University of Denmark, DK-2800 Kgs. Lyngby, Denmark \\ John P. O'Connell \\ Department of Chemical Engineering, University of Virginia, \\ Charlottesville, VA 22904-4741, U.S.A. \\ Preprint submitted for AIChE Journal
}

\begin{abstract}
A method is presented for predicting solubilities of solid solutes in mixed solvents, based on excess Henry's law constants. The basis is statistical mechanical fluctuation solution theory for composition derivatives of solute/solvent infinite dilution activity coefficients. Suitable approximations are made for a single parameter characterizing solute/solvent interactions. Comparisons with available data show that the method is successful in describing a variety of observed mixed solvent solubility behavior, including nearly ideal systems with small excess solubilities, systems with solute-independent excess solubilities, and systems deviating from these simple rules. Successful predictions for new solvent mixtures can be made using limited data from other mixtures.
\end{abstract}

Keywords: Excess solubility, solid solutes, mixed solvents, fluctuation solution theory, prediction and correlation

\footnotetext{
${ }^{*}$ Author to whom correspondence should be addressed. Tel.: (+45) 45252905. Fax: (+45) 45932906. E-mail: ja@kt.dtu.dk.
} 


\section{Introduction}

The solubility of solids in mixtures with one or more liquid solvents plays an important role in the design and production of traditional chemical and pharmaceutical products. While solubilities of solids in single solvents have been reported extensively ${ }^{1-3}$, the literature has fewer data on solubilities in mixed solvents. The dependence of these solubilities on solvent composition can be quite complex, ranging from linear to having extrema. Previously we have presented a method for predicting the solubility of a single solute in pure and mixed solvents ${ }^{4,5}$. That method was based on a 'reference solvent', in which the solubility is known and used to predict the solubility of the same solid species in other solvents. The method used differences between infinite dilution activity coefficients of the solute in different solvents, which might be calculated from group contribution methods such as UNIFAC. However, the selection of reference solvent is mostly empirical and substantial numbers of parameters may need to be determined from fitting to experimental data.

There are several other cosolvency models employed in the literature ${ }^{6}$. Such models express the solubility of the solute as a power series of the solute-free composition of the solvent using molecular descriptors. A method based more directly on fundamental theory may provide a more generalizable application especially as measurements of solid solubility data are now appearing frequently in the literature.

Here we provide an approach for correlating and estimating the 'excess' solubility or 'excess' Henry's law constant of a single solute in mixed solvents based on a solution

theory arising from statistical mechanics ${ }^{7,8}$. Previously ${ }^{9}$ a similar approach was taken to gas solubilities in mixed solvents. First, we give some basic definitions and expressions. Second, we present results of correlation and prediction of solubilities in mixed solvents 


\section{Thermodynamic Framework}

The 'excess' solubility is defined

$$
\ln x_{i}^{E} \equiv \ln x_{i, m}-\sum_{j \neq i} x_{j}^{\prime} \ln x_{i, j}
$$

where $x^{\prime}$ denotes a mole fraction on a solute-free basis. $x_{i, j}$ is the mole fraction solubility of species $i$ in pure solvent $j$, and $x_{i, m}$ is the solubility of solute $i$ in a mixed solvent. Using Lewis/Randall normalized solute liquid-phase activity coefficients $\left(\gamma_{i}\right)$, the solubility of a species, $i$, in a pure and mixed solvent can be written ${ }^{10}$

$$
\ln x_{i} \gamma_{i}(T, \mathbf{x}) \approx \frac{\Delta H_{m, i}}{R T_{m, i}}\left(1-\frac{T_{m, i}}{T}\right)
$$

The right-hand side of equation (2) does not depend on the nature of the solvent(s). It is a function only of the pure solute's melting properties. If the solubility in mole fraction is smaller than 0.01 , the activity coefficient of equation (2) can usually be approximated as the infinite dilution value, $\gamma_{i}^{\infty}$, and equation (1) may be written in terms of the infinite dilution Lewis/Randall normalized activity coefficients. With this approximation, inserting equation (2) into equation (1) gives

$$
\ln x_{i, m}-\sum_{j \neq i} x_{j}^{\prime} \ln x_{i, j} \approx-\ln \gamma_{i, m}^{\infty}+\sum_{j \neq i} x_{j}^{\prime} \ln \gamma_{i, j}^{\infty}
$$

The 'excess' Henry's law constant ${ }^{10,11}$ is defined by an equation similar to equation (1)

$$
\ln H_{i}^{E} \equiv \ln H_{i, m}-\sum_{j \neq i} x_{j}^{\prime} \ln H_{i, j}=\ln \gamma_{i, m}^{\infty}-\sum_{j \neq i} x_{j}^{\prime} \ln \gamma_{i, j}^{\infty}
$$

Thus,

$$
\ln H_{i}^{E} \equiv \ln H_{i, m}-\sum_{j \neq i} x_{j}^{\prime} \ln H_{i, j} \approx-\ln x_{i, m}+\sum_{j \neq i} x_{j}^{\prime} \ln x_{i, j}=-\ln x_{i}^{E}
$$




\section{Fluctuation Solution Theory Method}

The fluctuation solution theory (FST) of Kirkwood and Buff ${ }^{7}$ relates integrals of the statistical mechanical radial distribution function to solution isothermal compressibility, partial molar volumes, and composition derivatives of chemical potentials. O'Connell ${ }^{8}$ wrote the results in a more general and convenient matrix form, including formal expressions for multicomponent systems. The total correlation function integral (TCFI) between components $i$ and $j$ is

$$
H_{i j}=H_{j i}=\rho \int\left[g\left(r_{i j}\right)-1\right] \mathrm{d} v=\rho \int h_{i j} \mathrm{~d} v
$$

where $g$ is the radial (pair) distribution function between molecular centers of $i$ and $j, \rho$ is the bulk molecular solution density, and $v$ is the volume. The quantity $h_{i j}=g\left(r_{i j}\right)-1$ is called the total correlation function, and describes the overall correlation between $i$ and $j$ minus the bulk solution average of unity. Using this, exact expressions for composition derivatives may be written in terms of the TCFI. For a binary, one useful result is ${ }^{9}$

$$
\left(\frac{\partial \ln \gamma_{1}}{\partial x_{1}}\right)_{T, P, N_{2}}=-\frac{x_{2} f_{12}}{1+x_{1} x_{2} f_{12}}
$$

where the $f$-matrix is defined as

$$
f_{i j} \equiv H_{i i}+H_{j j}-2 H_{i j}
$$

The composition dependence of $H_{i j}$ is generally not known, so integrating equation (7) to obtain the activity coefficient is not possible. Alternatively, the activity coefficient may be expanded about a reference state of infinite dilution

$$
\ln \gamma_{i}=\left(\ln \gamma_{i}\right)_{x_{i}=0}+x_{i}\left(\frac{\partial \ln \gamma_{i}}{\partial x_{i}}\right)_{T, P, N_{j \neq i}, x_{i}=0}+\frac{x_{i}^{2}}{2 !}\left(\frac{\partial^{2} \ln \gamma_{i}}{\partial x_{i}^{2}}\right)_{T, P, N_{j \neq i}, x_{i}=0}+\ldots
$$

If equation (9) is assumed valid over the entire solvent composition range, the excess Henry's law constant of a single solute (1) in a mixed binary solvent (species 2 and 3) can 
be expressed as ${ }^{9}$

$$
\begin{aligned}
\ln H_{1}^{E}=\frac{x_{3}}{2}\left(\frac{\partial \ln \gamma_{3}}{\partial x_{3}}\right)_{T, P, N_{2}}^{+} & +\frac{x_{2}}{2}\left(\frac{f_{12}^{+}}{1+x_{2} x_{3} f_{23}^{+}}-f_{12}^{0}\right) \\
& +\frac{x_{3}}{2}\left(\frac{f_{13}^{+}}{1+x_{2} x_{3} f_{23}^{+}}-f_{13}^{0}\right) .
\end{aligned}
$$

Here ${ }^{+}$denotes infinite dilution of the solute in the mixed solvent and ${ }^{0}$ indicates infinite dilution in the single, pure solvent. The first term on the right-hand side of equation (10) is correct to all orders of equation (9). Thus, its contribution is not empirical. It may be calculated from any $G^{E}$-model. Similarly, $f_{23}^{+}$may be found from a rearranged form of equation (7), i.e.

$$
f_{23}^{+}=-\frac{\frac{1}{x_{2}}\left(\frac{\partial \ln \gamma_{3}}{\partial x_{3}}\right)_{T, P, N_{2}}^{+}}{1+x_{3}\left(\frac{\partial \ln \gamma_{3}}{\partial x_{3}}\right)_{T, P, N_{2}}^{+}} .
$$

While $f_{23}^{+}$in equation (10) can be found independently (usually from binary vapor/liquid equilibrium data forming the basis of a $G^{E}$-model) several other parameters may be involved; the solute/pure-solvent parameters $f_{12}^{0}$ and $f_{13}^{0}$, as well as one pair of mixture parameters $\left(f_{12}^{+}\right.$and $\left.f_{13}^{+}\right)$for each solvent composition. We assume that the 'mixture' terms $f_{12}^{+}$and $f_{13}^{+}$are equal to the corresponding 'pure solvent' terms, i.e.

$$
f_{i j}^{+} \triangleq f_{i j}^{0}
$$

The radial distribution function between components $i$ and $j$ is a measure of their total correlations, including indirect effects. The fact that $f_{12}^{+}$and $f_{13}^{+}$are differences, suggests that this approximation is reasonable except when solution density varies strongly with solute-free composition. This is rarely the case with solvent mixtures. The result is that the expression of the excess solubility in equation (1) simplifies to

$$
\ln x_{1}^{E}=-\frac{x_{3}}{2}\left(\frac{\partial \ln \gamma_{3}}{\partial x_{3}}\right)_{T, P, N_{2}}^{+}\left[1+x_{2} f_{12}^{0}+x_{3} f_{13}^{0}\right]
$$


The factors in equation (13) $-f_{12}^{0}$ and $f_{13}^{0}-$ can be found from linear regression. This technique minimizes a sum of squared residuals,

$$
\boldsymbol{\beta}=\operatorname{argmin}\left\{\sum_{i} r_{i}(\boldsymbol{\beta})^{2}\right\} .
$$

The vector $\boldsymbol{\beta}$ is the $f_{12}^{0}$ and $f_{13}^{0}$ values relevant to the problem considered. The elements of the residual vector, $\mathbf{r}$, are

$$
r_{i}=\left[\ln \hat{x}_{1}^{E}-\ln x_{1}^{E}\right]_{i}
$$

Here circumflex denotes a calculated value using equation (13). The linear estimation problem in equation (14) has a unique solution which is computationally favorable. Estimated variances of the parameters can be obtained from a variance-covariance matrix ${ }^{12}$.

We have used the diagonal terms of the variance-covariance matrix in a propagationof-errors expression to calculate the error bars of the figures below. The solute-free parameters for the Wilson equation are assumed to have zero variance.

\section{Results}

Combination of equations (5) and (10), allows us to reduce experimental excess solubility data for solid solutes in binary, mixed solvents. We have compiled 40 data sets of 5 solutes in a variety of solvent mixtures, ranging from almost ideal to strongly non-ideal solutions. Table 1 lists the solubility data with references. References are also given for the parameters characterizing the solvent-solvent non-ideality from binary vapor/liquid equilibrium data. Neither parameters nor data could be found for the solute-free binary of 1,2-propanediol and ethanol. For this case, the solvent parameters have been estimated from fitting Wilson equation ${ }^{13}$ activity coefficients to values calculated with the UNIFAC $\operatorname{model}^{14}$. 


\section{Excess Solubility in Binary Mixed Solvents - Correlation}

For parameter estimation all data sets in Table 1 are used. The rightmost column of Table 1 lists the average absolute deviation of the regressed mixtures, computed as

$$
\mathrm{AAD}=\frac{1}{M-2} \sum_{i}^{M}\left|r_{i}\right|
$$

excluding the pure solvent endpoints. Figure 1 shows data/model agreement in four representative systems where the solute-free binary solution is non-ideal. In Figures 1(a)-(c) the excess solubility is parabolic and the correlation performs satisfactorily. In Figure $1(d)$ the excess solubility is complex and changes sign but this is generally captured with the method. Standard deviations are provided as error bars on the calculated results at the experimental solvent compositions. Nearly all data points lie within the error bars. Parameters and standard deviations from regressing experimental data are shown in Table 2.

Figure 2 shows two systems where the solute-free binaries form nearly ideal solutions. The agreement is more qualitative, and certainly not as good as shown in Figure 1. Extensive examination of solute-free binaries ${ }^{15}$ show that a maximum in $f_{23}^{+}$is usually found in mixtures with strong solvent non-ideality, whereas the $f_{23}^{+}$in nearly ideal mixtures (where the absolute magnitude of $f_{23}^{+}$is $<2$ ) are generally monotonic. Figure 3 shows $f_{23}^{+}$plotted as a function of composition for the nearly ideal binary solution of chlorobenzene/aniline and the strongly non-ideal case of ethanol/n-heptane. In general we have found that parameters estimated from mixtures where the solute-free binary is nearly ideal usually have larger standard deviations while those found for non-ideal mixtures have lower standard deviations. This indicates that estimation of parameters characterizing the solute-solvent interaction is best done in mixtures where the solute-free binary forms a substantially non-ideal solution. Mixtures with numerically small values of $f_{23}^{+}$are largely insensitive to changes in $f_{1 j}^{0}$. This means that the excess solubilities in these mixtures are small and approximately independent of the nature of the solute. 


\section{Excess Solubility in Binary Mixed Solvents - Prediction}

To test the predictive capability of the approach, Figure 4 shows an example of two moderately successful predictions of data sets 15 and 17 in Table 1 . The excess solubility prediction of Figure 4 require measured solubility data in four systems for estimation of the parameter values between beta carotene and each of the solvents. The parameters used in Figure 4 are based on simultaneous reduction of the sets 13, 14, 16 and 18, giving the $f_{1 j}^{0}$ values for beta carotene (1) with ${ }^{\prime} j^{\prime}=$ acetone $(1.88 \pm 0.47)$, toluene (10.36 \pm 3.97$)$, MEK $(6.14 \pm 0.69)$ and hexane $(2.87 \pm 0.50)$. These parameters are different from those in Table 2, because prediction is tested here. Figure 4 shows trends of the excess solubility which are qualitatively correct and the experimental results are within the error bars.

Table 3 shows values of estimated parameters for paracetamol (solute) with four different solvents estimated from four different sets of measured data, labeled I-IV. The sets of data in I are 3 and 6 from Table 1 giving parameter values for predicting the excess solubility in sets 1,4 and 5 . We have excluded set 2 in this procedure because dioxane only appears in a single data set. Similar combinations of training/testing sets may be built as shown in Figure 5. On the left is shown the data sets used for estimation of the paracetamol/solvent parameter values. These are then used to predict the excess solubility in the mixtures shown on the right. The estimated parameter values are listed in Table 3 according to their position in Figure 5. Table 3 shows that the procedure chosen from Figure 5 requires relatively little alteration of the parameter values, except for that characterizing paracetamol with methanol. However, the standard deviation for this system is significantly larger compared to the others. These results suggest that the method can reproduce consistent parameter values using different combinations of data from different sources. Figure 6 shows examples of the predicted excess solubility of paracetamol in two solvent mixtures. The estimates in Figure 6(a) were made from procedure I of Figure 5 and 6(b) using method IV. Although several data points are outside the range of the prediction intervals, the trends are correct. In particular, the asymmetry of the curve of Figure $6(\mathrm{~b})$ is consistent with the experimental data. 


\section{Discussion}

The discrepancy among the paracetamol/methanol parameters obtained is probably related to the type of experimental data used. Models originating from fluctuation solution theory work best - in predictive mode - for non-ideal systems, and may not describe more ideal systems as well. Methanol forms ideal or close-to-ideal solutions with water, ethanol, and ethyl acetate.

The system water and 1,2-propanediol was not easily described with the above approach. The predictions for Figures $7(\mathrm{a})$ and $7(\mathrm{~b})$ predict a region of negative excess solubility which is not confirmed by the data. To examine this problem, an attempt was made to revise the binary solvent parameters using the mixed solvent data with naphthalene. The resulting solvent parameters were inconsistent with VLE data ${ }^{16}$, suggesting a basic inconsistency of the model and the data. Since the discrepancy is found when the solvent mixture is nearly pure water, the model concept might not be appropriate for hydrophobic attractions of the solute and the dilute nonaqueous solvent. This suggests that careful evaluation of the input data, both excess solubility and the underlying data used to construct the composition dependence of $f_{23}^{+}$, will be well worth the effort if quantitative agreement is to be reached in complex cases.

The formalism presented in this paper assumes infinite dilution of the solute, thereby removing solute/solute interactions from the mixture. An expected application is solubility enhancement of such substances as pharmaceuticals and biochemicals. Systems in these categories usually have very low solubilities, below the limit of infinite dilution. However, in cases where the solubility exceeds $1 \%$, equation (3) may not be valid. System 6 of Table 1 of paracetamol with methanol and ethanol ${ }^{17}$ has the the mole fraction solubility of paracetamol varying from 0.0019 (in water) to 0.0542 (in ethanol). However, the correlation performs well. This suggests that the method is capable of describing the excess solubility in some mixtures with high solubilities, though further investigation of this possibility is needed. 


\section{Extension to Multicomponent Solvent Mixtures}

Application of the method to mixtures containing more than two solvent species requires a revision of the compositional dependence of the solute activity coefficient. The expansion of the activity coefficient about a reference state of infinite dilution in equation (9) has been done only for binary and ternary mixtures ${ }^{8}$. O'Connell ${ }^{8}$ presents a general multicomponent expression for the compositional derivative of the chemical potential, and hence the activity coefficient, with constant temperature, pressure and mole number of other species as a function of the total correlation function integral, given by equation (6). Higher order derivative terms can be found from the expansion in equation (9), a change in variables, and differentiation of the expression obtained for the derivative.

\section{Conclusions}

A theoretical modeling framework has been used to correlate and predict the excess solubilities of solid solutes in a variety of binary solvent mixtures. The model uses one parameter characterizing solute-solvent interaction and an activity coefficient model for the solute-free solvent mixture. The proposed method successfully describes excess solubility behavior in most systems with nearly-ideal solvents and all strongly non-ideal solvent systems, including those with double extrema in the excess solubility. Prediction of solubilities in pairs of solvents can be made from results found from other mixtures containing the solvent components.

\section{Notation}

$f \quad=$ Set of pair correlation function integrals, eq. (8)

$g \quad=$ Radial (pair) distribution function

$G \quad=$ Gibbs energy

$h=$ Total correlation function, $g-1$

$H=$ Henry's constant 


$$
\begin{array}{ll}
H & =\text { Total correlation function integral } \\
N & =\text { Mole number } \\
P & =\text { Pressure } \\
r & =\text { Distance between molecular centers } \\
r & =\text { Residual } \\
R & =\text { Universal gas constant }\left(8.314 \mathrm{~J} \mathrm{~mol}^{-1} \mathrm{~K}^{-1}\right) \\
T & =\text { Absolute temperature } \\
v & =\text { Volume } \\
x & =\text { Mole fraction }
\end{array}
$$

\section{Greek letters}

$$
\begin{aligned}
& \boldsymbol{\beta}=\text { Parameter set, }\left\{f_{12}^{0}, f_{13}^{0}\right\} \\
& \gamma \quad=\text { Activity coefficient } \\
& \Delta H=\text { Enthalpy of fusion } \\
& \rho \quad=\text { Molar density } \\
& \sigma \quad=\text { Standard deviation of variables }
\end{aligned}
$$

\section{Subscripts and superscripts}

$$
\begin{aligned}
{ }_{1} & =\text { Solute free basis } \\
\infty & =\text { Calculated value } \\
+ & =\text { Infinite dilution } \\
0 & =\text { Infinite dilution of solute in mixed solvent } \\
E & =\text { Excess property } \\
i, j & =\text { Components } \\
m & =\text { Fusion or mixture property }
\end{aligned}
$$




\section{Literature Cited}

1. Nielsen TL, Abildskov J, Harper PM, Papaeconomou I, Gani R. The CAPEC database. Journal of Chemical and Engineering Data. 2001;46:1041-1044.

2. Marrero J, Abildskov J. Solubility and Related Properties of Large Complex Chemicals - Part 1: Organic Solutes ranging from C4 to C40., vol. 15 of DECHEMA Chemistry Data Series. Frankfurt am Main: DECHEMA. 2003.

3. Abildskov J. Solubility and Related Properties of Large Complex Chemicals - Part 2., vol. 15 of DECHEMA Chemistry Data Series. Frankfurt am Main: DECHEMA. 2005.

4. Abildskov J, O'Connell JP. Predicting the solubilities of complex medium-sized chemicals II. Solutes in mixed solvents. Molecular Simulation. 2004;30(6):367-378.

5. Abildskov J, O'Connell JP. Thermodynamic method for obtaining the solubilities of complex medium-sized chemicals in pure and mixed solvents. Fluid Phase Equilibria. 2005;228-229:395-400.

6. Jouyban A, Chew NYK, Chan HK, Sabour M, Acree Jr WE. A unified cosolvency model for calculating solute solubility in mixed solvents. Chemical $\&$ Pharmaceutical Bulletin. 2005;53(6):634-637.

7. Kirkwood JG, Buff FP. The statistical mechanical theory of solutions. Journal of Chemical Physics. 1951;19(8):774-777.

8. O'Connell JP. Thermodynamic properties of solutions based on correlation functions. Molecular Physics. 1971;20(1):27-33.

9. O'Connell JP. Molecular thermodynamics of gases in mixed solvents. AIChE Journal. 1971;17(3):658-663.

10. Prausnitz JM, Lichtenthaler RN, de Azevedo EG. Molecular thermodynamics of fluidphase equilibria. Prentice-Hall. 1986.

11. O'Connell JP, Prausnitz JM. Thermodynamics of gas solubility in mixed solvents. Industrial $\&$ Engineering Chemistry Fundamentals. 1964;2:347-351.

12. Fletcher R. Practical methods of optimization. Wiley. 1987.

13. Wilson GM. Vapor-liquid equilibrium. XI. A new expression for the excess free energy of mixing. Journal of the American Chemical Society. 1964;86(2):127-130. 
14. Hansen HK, Coto B, Kuhlmann B. UNIFAC with lineary temperature-dependent group-interaction parameters. 1992. SEP 9212 (Internal note at the Department of Chemical Engineering, Technical University of Denmark), Lyngby, Denmark.

15. Wooley RJ, O'Connell JP. A database of fluctuation thermodynamic properties and molecular correlation function integrals for a variety of binary liquids. Fluid Phase Equilibria. 1991;66:233-261.

16. Gmehling J, Onken U, Arlt W, Weidlich U, Grenzheuser P, Kolbe B. Vapor-Liquid Equilibrium Data Collection, Part 1. Chemistry Data Series. Frankfurt: DECHEMA. 1977-1984.

17. Subrahmanyam CVS, Reddy MS, Rao JV, Rao PG. Irregular solution behaviour of paracetamol in binary solvents. International Journal of Pharmaceutics. 1992;78:1724.

18. Romero S, Reillo A, Escalera B, Bustamente P. The behavior of paracetamol in mixtures of amphirotic and amphiprotic-aprotic solvents. Relationship of solubility curves to specific and nonspecific interactions. Chemical \& Pharmaceutical Bulletin. 1996;44(5):1061-1064.

19. Acree Jr W, Bertrand G. Thermochemical investigations of nearly ideal binary solvents VII: Monomer and dimer models for solubility of benzoic acid in simple binary and ternary solvents. Journal of Pharmaceutical Sciences. 1981;70:1033-1036.

20. Bissell TG, Williamson AG. Vapour pressures and excess Gibbs energies of n-hexane and of n-heptane + carbon tetrachloride and + chloroform at $298.15 \mathrm{~K}$. Journal of Chemical Thermodynamics. 1975;7:131-136.

21. Treszczanowicz T, Treszczanowicz AJ, Kasprzycka-Guttman T, Kulesza A. Solubility of beta-carotene in binary solvents formed by some hydrocarbons with ketones. Journal of Chemical and Engineering Data. 2001;46(4):792-794.

22. Zvaigzne A, Teng I, Martinez E, Trejo J, Acree Jr W. Solubility of anthracene in binary alkane +1 -propanol and alkane +1 -butanol solvent mixtures. Journal of Chemical and Engineering Data. 1993;38:389-392.

23. Gracia M, Sanchez F, Perez P, Valero J, Losa CG. Vapour pressures of $x$ C4H9OH 
$+(1-x)$ C8H18 $(l)$ at temperatures between $283.16 \mathrm{~K}$ and $323.18 \mathrm{~K}$. Journal of Chemical Thermodynamics. 1992;24:843-849.

24. Zvaigzne AI, Acree Jr WE. Solubility of anthracene in binary alkane +2 -butanol solvent mixtures. Journal of Chemical and Engineering Data. 1994;39:114-116.

25. Zvaigzne A, Wolfe J, Acree Jr W. Solubility of anthracene in binary alkane +2 methyl-1-propanol solvent mixtures. Journal of Chemical and Engineering Data. 1994; 39:541-543.

26. Rodriguez V, Pardo J, Lbpez MC, Royo FM, , Urieta JS. Vapor pressures of binary mixtures of hexane + l-butanol, + 2-butanol, +2 -methyl-l-propanol, or +2 -methyl2-propanol at 298.15 K. Journal of Chemical and Engineering Data. 1993;38:350-352.

27. Heintz A, Dolch E, Lichtenthaler RN. New experimental VLE-data for alkanol/alkane mixtures and their description by an extended real association (ERAS) model. Fluid Phase Equilibria. 1986;27:61-79.

28. Zvaigzne AI, Acree Jr WE. Thermochemical investigation of molecular complexation: Estimation of anthracene-ethyl acetate and anthracene-diethyl adipate association parameters from measured solubility data. Physics and Chemistry of Liquids. 1991;24:31-42.

29. Zielkiewicz J. (Vapour + liquid) equilibria in (propan-1-ol + heptane + octane) at the temperature 313.15 K. Journal of Chemical Thermodynamics. 1992;24(5):455-462.

30. Powell JR, McHale MER, Kauppila ASM, Acree Jr WE. Solubility of anthracene in binary alcohol +2 -pentanol and alcohol +4 -methyl-2-pentanol solvent mixtures. Journal of Chemical and Engineering Data. 1996;41(4):728-730.

31. Mara K, Bhethanabotla VR, Campbell SW. Total pressure measurements for 1propanol + 1-pentanol, 1-propanol + 2-pentanol, 2-propanol +1 -pentanol, and 2propanol + 2-pentanol at 313.15 K. Fluid Phase Equilibria. 1997;127:147-153.

32. McHale MER, Kauppila ASM, Acree Jr WE. Solubility of anthracene in binary alkane + methyl tert-butyl ether solvent mixtures at $298.15 \mathrm{~K}$. Journal of Chemical and Engineering Data. 1996;41(5):1203-1205.

33. Lozano LM, Montero EA, Martin MC, Villamanan MA. Vapor-liquid equilibria of 
binary mixtures containing methyl tert-butyl ether (MTBE) and/or substitution hydrocarbons at 298.15 K and 313.15 K. Fluid Phase Equilibria. 1995;110:219-230.

34. Lepree JM, Mulski MJ, Connors KA. Solvent effects on chemical processes. Part 6. The phenomenological model applied to the solubility of naphthalene and 4-nitroaniline in binary aqueous-organic solvent mixtures. Journal of the Chemical Society, Perkin Transactions 2. 1994;2:1491-1497.

35. Lancia A, Musmarra D, Pepe F. Vapor-liquid equilibria for mixtures of ethylene glycol, propylene glycol, and water between $98^{\circ}$ and $122^{\circ} \mathrm{C}$. Journal of Chemical Engineering of Japan. 1996;29(3):449-455.

36. Jouyban A, Chew NYK, Chan HK, Khoubnasabjafari M, Acree Jr WE. Solubility prediction of salicylic acid in water-ethanol-propylene glycol mixtures using the Jouyban-Acree model. Pharmazie. 2006;61(4):318-321.

\section{Figure Captions}

Figure 1. Estimated and experimental excess solubility of solid solutes in binary mixed solvents: (a) Naphthalene(1) / water(2) / acetone, (b) anthracene(1) / n-octane(2) / 1-butanol(3), (c) beta carotene(1) / acetone(2) / n-hexane(3), and (d) salicylic $\operatorname{acid}(1) /$ ethanol(2) / water(3). The solute-free binary mixture forms a non-ideal solution in all of these systems.

Figure 2. Estimated and experimental excess solubility of solid solutes in binary mixed solvents: (a) Paracetamol(1) / methanol(2) / water(3), and (b) beta carotene(1) / $\operatorname{MEK}(2)$ / toluene(3). The solute-free binary mixture forms a close-to-ideal solution in these systems, and the data/model agreement is not as good as that in the more non-ideal mixtures.

Figure 3. Total correlation function integral factor $f_{23}^{+}$of a nearly ideal and a non-ideal system. The values of chlorobenzene/aniline refers to the right ordinate, while ethanol/n-heptane refers to the left ordinate. Data taken from ${ }^{15}$. 
Figure 4. Predicted and experimental excess solubility of beta carotene in binary solvent mixtures: (a) Beta carotene(1) / acetone(2) / toluene(3), and (b) beta carotene(1) / $\operatorname{MEK}(2)$ / n-hexane(3).

Figure 5. Graphical display of estimation/prediction procedure with varying amount of input data (left side) used to predict the excess solubility in the output (right side). The listed items are the solvent mixtures in which the solute is dissolved.

Figure 6. Predicted and experimental excess solubility of paracetamol in binary solvent mixtures: (a) Paracetamol(1) / ethyl acetate(2) / ethanol(3), and (b) paracetamol(1) / water(2) / ethanol(3).

Figure 7. Estimated and experimental excess solubility of naphthalene and salicylic acid in 1,2-propanediol and water: (a) Naphthalene(1) / water(2) / 1,2-propanediol(3), and (b) salicylic acid(1) / 1,2-propanediol(2) / water(3).

\section{Figures and Tables}




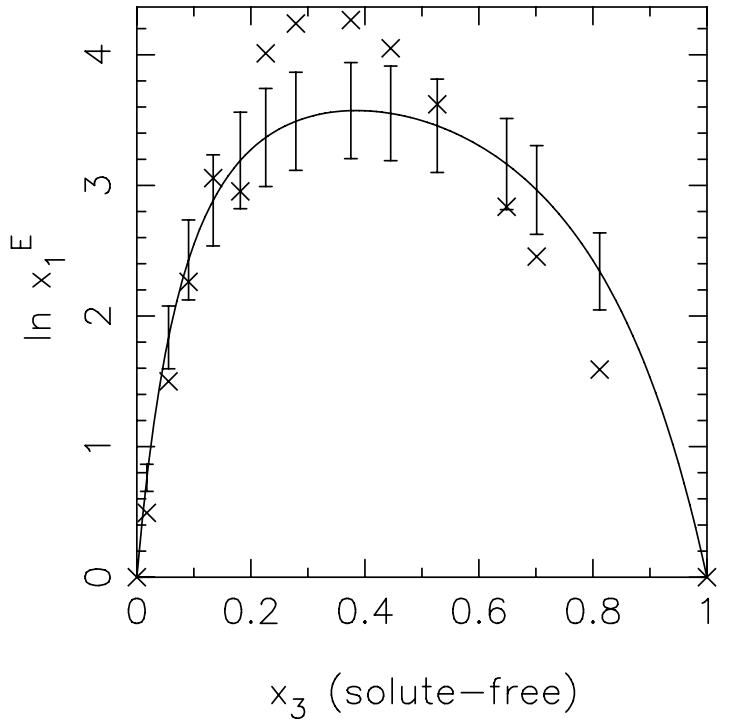

(a)

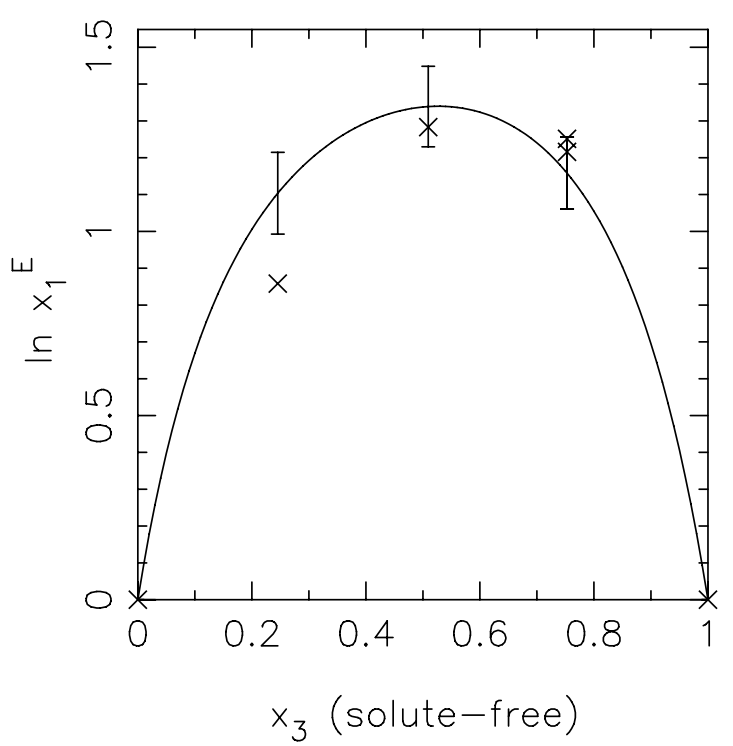

(c)

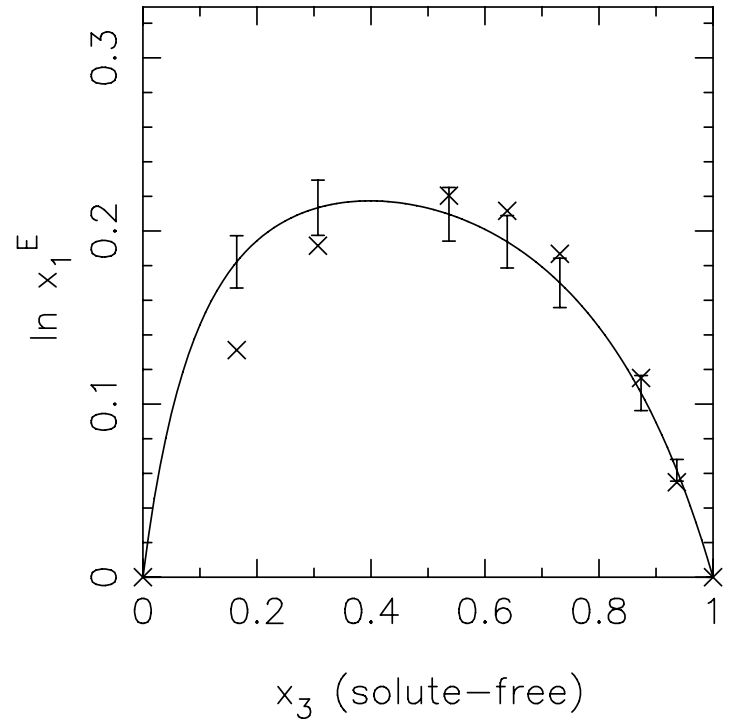

(b)

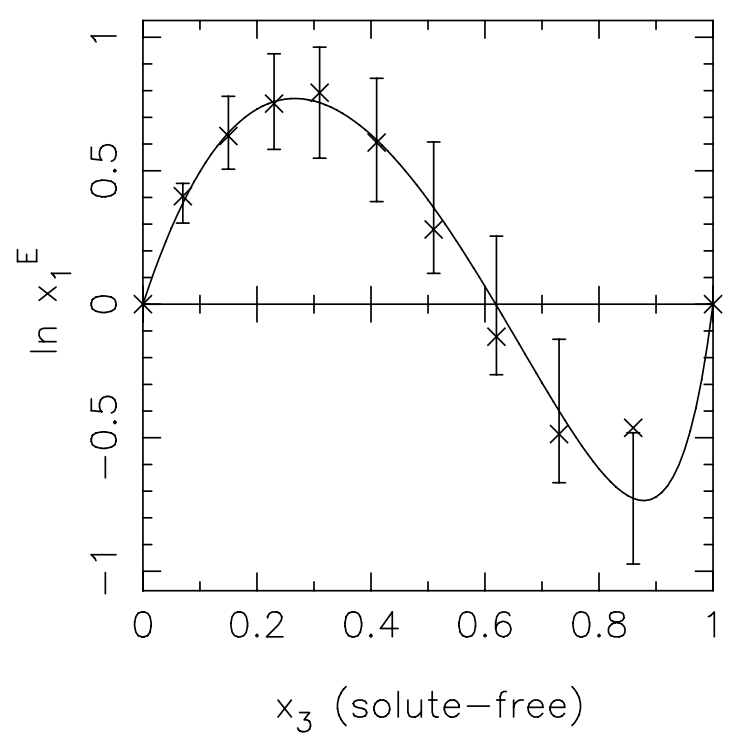

(d)

Figure 1 


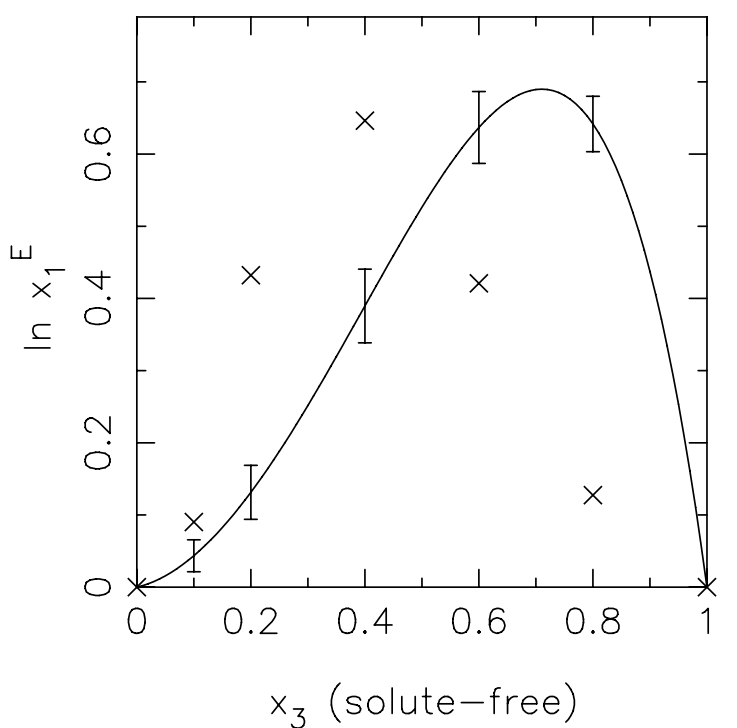

(a)

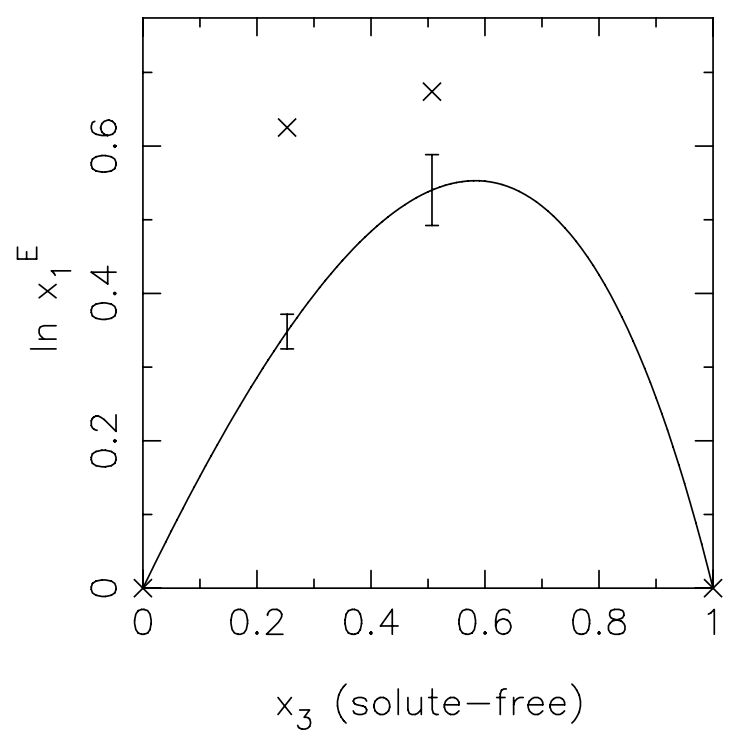

(b)

Figure 2

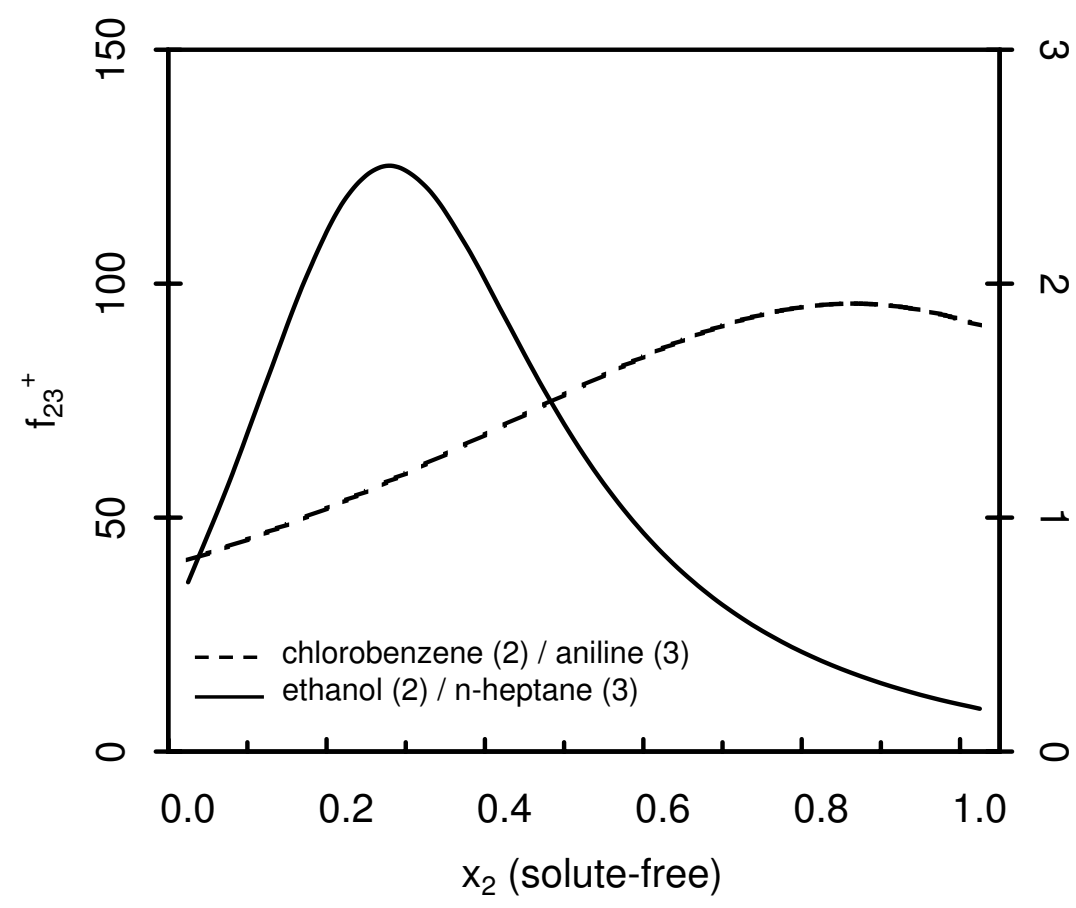

Figure 3 


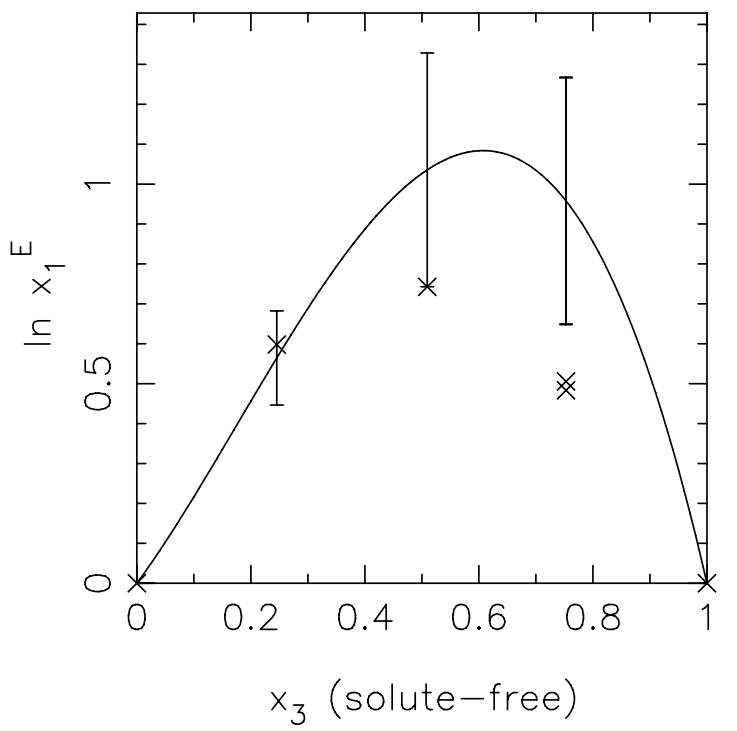

(a)

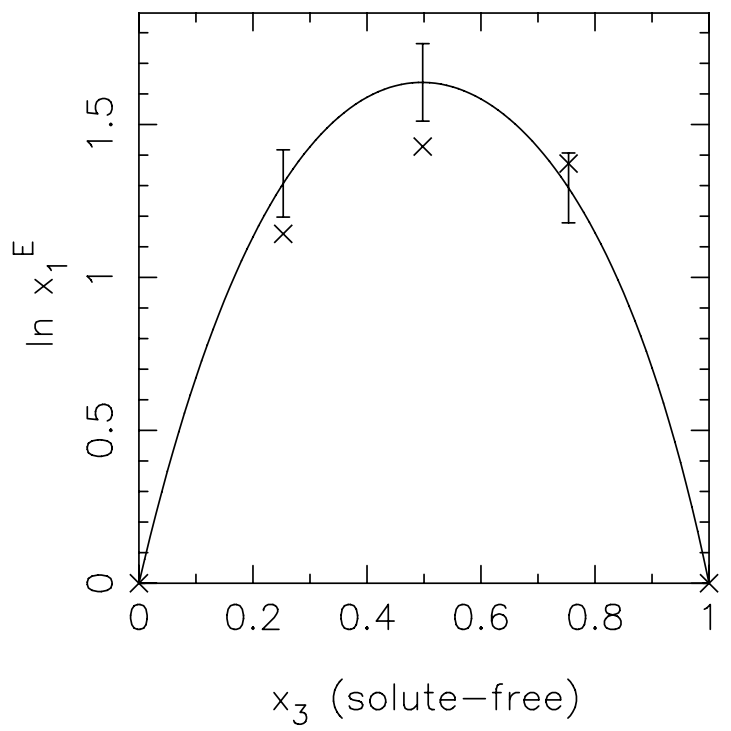

(b)

Figure 4

I

Ethanol-Water

Ethyl Acetate - Methanol

Ethanol - Water

Methanol - Water

II Methanol - Water
Ethyl Acetate - Ethanol

III

Ethyl Acetate - Methanol

Methanol - Water

Ethanol - Water

IV

Methanol - Water

Ethyl Acetate - Methanol

Ethyl Acetate - Ethanol

Ethanol-Methanol.
Ethanol - Methanol
Ethyl Acetate - Ethanol

Methanol - Water

Ethanol - Methanol Ethyl Acetate - Methanol

Correlation

Ethyl Acetate - Ethanol

Ethanol-Methanol

Ethanol - Water

Figure 5 


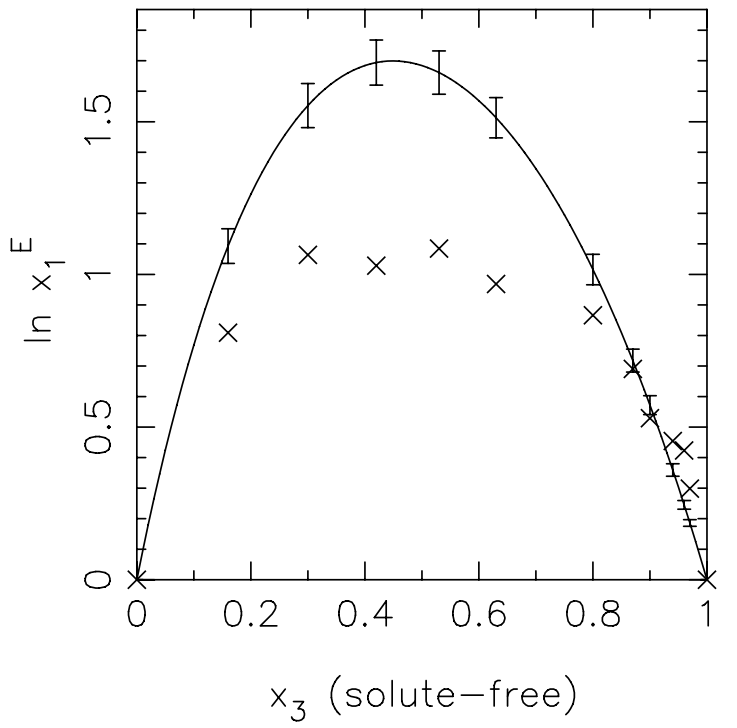

(a)

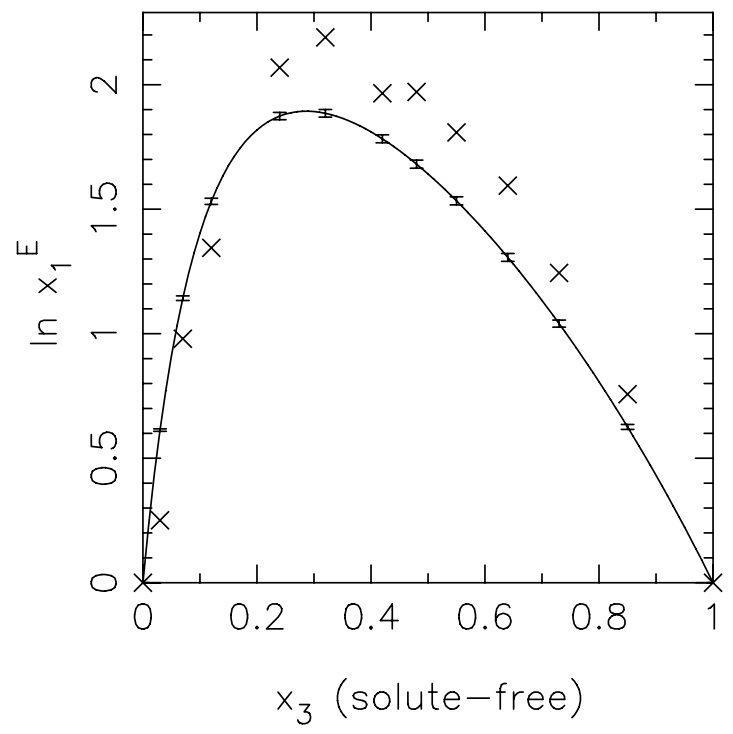

(b)

Figure 6

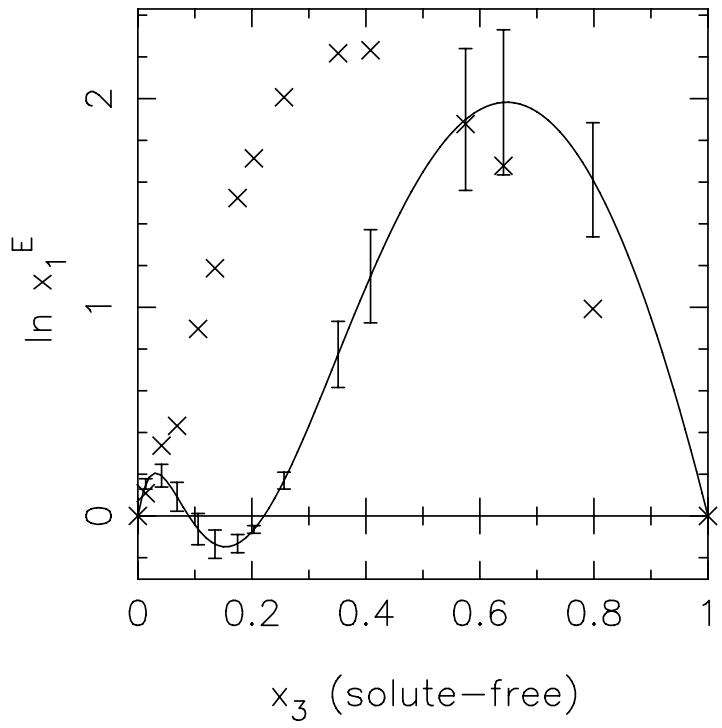

(a)

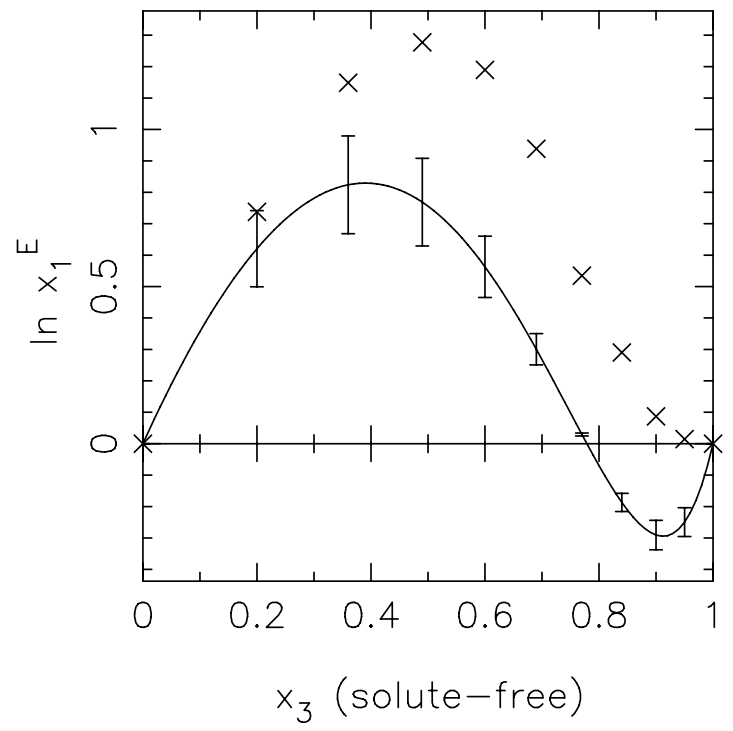

(b)

Figure 7 
Table 1. Experimental data used; SLE for solubilities, VLE for solvent mixture non-ideality. Number of experimentally measured solubilities in each system includes solubilities in pure solvents.

\begin{tabular}{|c|c|c|c|c|c|c|c|}
\hline \multirow[b]{2}{*}{ No. } & \multirow[b]{2}{*}{ Solute (1) } & \multirow[b]{2}{*}{ Solvent (2) } & \multirow[b]{2}{*}{ Solvent (3) } & \multirow{2}{*}{$\begin{array}{c}\text { Number } \\
\text { of data } \\
\text { points }\end{array}$} & \multicolumn{2}{|c|}{ Reference } & \multirow[b]{2}{*}{$\mathrm{AAD}$} \\
\hline & & & & & SLE & VLE & \\
\hline 1 & Paracetamol & ethyl acetate & ethanol & 13 & 18 & 16 & 0.1720 \\
\hline 2 & Paracetamol & water & 1,4-dioxane & 17 & 18 & 16 & 0.1951 \\
\hline 3 & Paracetamol & ethyl acetate & methanol & 14 & 17 & 16 & 0.0165 \\
\hline 4 & Paracetamol & methanol & water & 7 & 17 & 16 & 0.0262 \\
\hline 5 & Paracetamol & ethanol & methanol & 3 & 17 & 16 & 0.0008 \\
\hline 6 & Paracetamol & water & ethanol & 13 & 18 & 16 & 0.0733 \\
\hline 7 & Benzoic acid & carbon tetrachloride & n-heptane & 10 & 19 & 20 & 0.0248 \\
\hline 8 & Benzoic acid & n-heptane & cyclohexane & 7 & 19 & 16 & 0.0166 \\
\hline 9 & Benzoic acid & carbon tetrachloride & n-hexane & 7 & 19 & 16 & 0.0046 \\
\hline 10 & Benzoic acid & carbon tetrachloride & cyclohexane & 7 & 19 & 16 & 0.0051 \\
\hline 11 & Benzoic acid & carbon tetrachloride & n-heptane & 6 & 19 & 20 & 0.0029 \\
\hline 12 & Benzoic acid & n-hexane & cyclohexane & 7 & 19 & 16 & 0.0048 \\
\hline 13 & Beta carotene & acetone & cyclohexane & 6 & 21 & 16 & 0.0726 \\
\hline 14 & Beta carotene & acetone & n-hexane & 6 & 21 & 16 & 0.0115 \\
\hline 15 & Beta carotene & acetone & toluene & 6 & 21 & 16 & 0.0153 \\
\hline 16 & Beta carotene & MEK & cyclohexane & 8 & 21 & 16 & 0.0127 \\
\hline 17 & Beta carotene & MEK & n-hexane & 5 & 21 & 16 & 0.0078 \\
\hline 18 & Beta carotene & MEK & toluene & 5 & 21 & 16 & 0.0209 \\
\hline 19 & Anthracene & n-hexane & 1-butanol & 9 & 22 & 16 & 0.0326 \\
\hline 20 & Anthracene & n-hexane & 1-propanol & 9 & 22 & 16 & 0.0129 \\
\hline 21 & Anthracene & n-heptane & 1-propanol & 9 & 22 & 16 & 0.0056 \\
\hline 22 & Anthracene & cyclohexane & 1-propanol & 9 & 22 & 16 & 0.0074 \\
\hline 23 & Anthracene & n-octane & 1-butanol & 9 & 22 & 23 & 0.0034 \\
\hline 24 & Anthracene & n-hexane & 2-butanol & 9 & 24 & 16 & 0.0024 \\
\hline 25 & Anthracene & n-hexane & 2-methyl-1-propanol & 9 & 25 & 26 & 0.0020 \\
\hline 26 & Anthracene & n-heptane & 2-methyl-1-propanol & 9 & 25 & 27 & 0.0052 \\
\hline 27 & Anthracene & cyclohexane & ethyl acetate & 9 & 28 & 16 & 0.0061 \\
\hline 28 & Anthracene & n-octane & 1-propanol & 9 & 22 & 29 & 0.0022 \\
\hline 29 & Anthracene & n-heptane & 1-butanol & 9 & 22 & 16 & 0.0020 \\
\hline 30 & Anthracene & 1-propanol & 2-pentanol & 9 & 30 & 31 & 0.0011 \\
\hline 31 & Anthracene & 2-propanol & 2-pentanol & 9 & 30 & 31 & 0.0016 \\
\hline 32 & Anthracene & cyclohexane & MTBE & 9 & 32 & 33 & 0.0015 \\
\hline 33 & Naphthalene & water & methanol & 14 & 34 & 16 & 0.0740 \\
\hline 34 & Naphthalene & water & ethanol & 15 & 34 & 16 & 0.1745 \\
\hline 35 & Naphthalene & water & 2-propanol & 12 & 34 & 16 & 0.1234 \\
\hline 36 & Naphthalene & water & 1,2-propanediol & 15 & 34 & 35 & 0.2063 \\
\hline 37 & Naphthalene & water & acetone & 15 & 34 & 16 & 0.0777 \\
\hline 38 & Salicylic acid & 1,2-propanediol & water & 11 & 36 & 35 & 0.3490 \\
\hline 39 & Salicylic acid & 1,2-propanediol & ethanol & 11 & 36 & * & 0.1354 \\
\hline 40 & Salicylic acid & ethanol & water & 11 & 36 & 16 & 0.0195 \\
\hline
\end{tabular}

* Parameters for the solute-free binary estimated from UNIFAC ${ }^{14}$. 
Table 2. Estimated values of the parameters in equation (13) and their corresponding standard deviations found from optimization.

\begin{tabular}{|c|c|c|c|}
\hline Solute (1) & Solvent (2) & $f_{12}^{0}$ & $\sigma$ \\
\hline beta carotene & acetone & 1.92 & 0.40 \\
\hline beta carotene & cyclohexane & 3.87 & 0.33 \\
\hline beta carotene & n-hexane & 2.82 & 0.38 \\
\hline beta carotene & toluene & 5.75 & 1.09 \\
\hline beta carotene & MEK & 5.81 & 0.49 \\
\hline benzoic acid & carbon tetrachloride & -0.11 & 0.77 \\
\hline benzoic acid & n-heptane & -2.47 & 1.37 \\
\hline benzoic acid & n-hexane & 0.07 & 1.01 \\
\hline benzoic acid & cyclohexane & -0.03 & 0.98 \\
\hline paracetamol & ethyl acetate & 5.95 & 1.04 \\
\hline paracetamol & water & 8.70 & 0.54 \\
\hline paracetamol & methanol & -0.40 & 0.85 \\
\hline paracetamol & ethanol & 1.82 & 0.88 \\
\hline paracetamol & dioxane & 3.61 & 0.79 \\
\hline anthracene & n-hexane & -0.77 & 0.04 \\
\hline anthracene & n-heptane & -0.63 & 0.04 \\
\hline anthracene & n-octane & -0.49 & 0.05 \\
\hline anthracene & cyclohexane & -0.54 & 0.06 \\
\hline anthracene & 2-methyl-1-propanol & 0.28 & 0.08 \\
\hline anthracene & 1-propanol & -0.15 & 0.05 \\
\hline anthracene & 1-butanol & -0.44 & 0.06 \\
\hline anthracene & 2-propanol & 1.70 & 4.04 \\
\hline anthracene & 2-butanol & 0.40 & 0.12 \\
\hline anthracene & 2-pentanol & 4.86 & 4.17 \\
\hline anthracene & ethyl acetate & 1.56 & 0.11 \\
\hline anthracene & MTBE & 8.02 & 1.03 \\
\hline naphthalene & water & 7.15 & 1.13 \\
\hline naphthalene & methanol & 18.45 & 5.31 \\
\hline naphthalene & ethanol & 7.20 & 1.89 \\
\hline naphthalene & 2-propanol & 9.46 & 1.89 \\
\hline naphthalene & 1,2-propanediol & -84.06 & 13.75 \\
\hline naphthalene & acetone & 7.70 & 1.31 \\
\hline salicylic acid & 1,2-propanediol & -31.38 & 6.13 \\
\hline salicylic acid & ethanol & 5.46 & 1.21 \\
\hline salicylic acid & water & -4.98 & 0.97 \\
\hline
\end{tabular}


Table 3. Estimated parameter values (standard deviation in parenthesis) between paracetamol and solvents. Numerals I-IV refer to values obtained from regression of different sets of experimental data as in Figure 5.

\begin{tabular}{llcccc}
\hline \multirow{2}{*}{ Solute (1) } & \multirow{2}{*}{ Solvent (2) } & \multicolumn{4}{c}{$f_{12}^{0}(\sigma)$} \\
\cline { 3 - 6 } & & I & II & III & IV \\
\hline Paracetamol & ethyl acetate & $6.68(0.46)$ & $6.80(0.16)$ & $5.77(0.07)$ & $5.13(0.53)$ \\
Paracetamol & methanol & $-0.83(0.32)$ & $4.81(1.71)$ & $4.81(1.71)$ & $0.11(0.41)$ \\
Paracetamol & water & $4.28(0.28)$ & $4.13(0.37)$ & $4.13(0.37)$ & $4.83(1.67)$ \\
Paracetamol & ethanol & $5.76(0.41)$ & $5.91(0.53)$ & $5.91(0.53)$ & $3.58(0.68)$ \\
\hline
\end{tabular}

